\title{
WOOD CHIPS ASH PROCESSING AND ITS UTILIZATION IN MAGNESIUM PHOSPHATE CEMENT COMPOSITES
}

\author{
\#ONDŘEJ JANKOVSKÝ*, VILÉM BARTU゚NĚK*, FILIP ANTONČÍK*, ADÉLA JIŘÍČKOVÁ*, \\ ANNA-MARIE LAUERMANNOVÁ*, MARTINA ZÁLESKÁ**, MILENA PAVLÍKOVÁ**, \\ JAROSLAV POKORNÝ**, ZBYŠEK PAVLÍK** \\ * Department of Inorganic Chemistry, Faculty of Chemical Technology, University of Chemistry and Technology Prague, \\ Technická 5, 16628 Prague 6, Czech Republic \\ ** Department of Materials Engineering and Chemistry, Faculty of Civil Engineering, Czech Technical University in Prague, \\ Thákurova 7, 16629 Prague 6, Czech Republic \\ "E-mail: Ondrej.Jankovsky@vscht.cz
}

Submitted April 3, 2019; accepted May 10, 2019

\begin{abstract}
Keywords: Biomass, Wood chips ash processing, Materials Sintering, Magnesium phosphate cement composites, Microfiller
In this paper, we demonstrated that wooden chips ash can be further processed and selected products of its treatment can be used as additives in magnesium phosphate cement composites. Wooden chips ash, as well as obtained products, were analysed by XRF, XRD, SEM, EDS, STA. Also, the particle size of the obtained fractions was analysed using laser diffraction. Basic structural properties, bulk density, specific density, total open porosity and pore size distribution of prepared composite material in comparison to the reference were measured. In addition, mechanical properties were also tested. The newly developed composite with incorporated fractions of wood chips ash showed acceptable structural and mechanical properties that were almost unchanged compared to the reference sample without any biomass-based additives.
\end{abstract}

\section{INTRODUCTION}

Biomass is one of the most promising possible renewable energy sources. It is available in many regions and it is easily processed and stored which allow the deployment of relevant and local bioenergy virtually everywhere $[1,2]$. In larger volumes, biomass can be used for the production of solid, liquid and also gas forms according to its application and the needs of facilities. From the above results that in comparison with solar and wind technologies the biomass-based technologies have low dependence on the weather and climatic unbalances [3]. Also, the technologies used are established, well known and with good performance. Woodchips are particularly cheap and available fuel with quite a low energy production requirements. Also, it has a very stable burning performance because of the relatively large contact surface compared with other solid biofuels [4]. Its usefulness can be especially highlighted when applied in the case of decentralized energy systems based on local renewable energy sources [5, 6]. Presence of some elements $(\mathrm{Cl}, \mathrm{P}, \mathrm{Na}, \mathrm{K})$ which forms low melting salts with corrosion potential [7] may be a negative aspect of woodchip usage in some cases.

Since the production of energy from biomass combustion is continuously increasing, the processing and disposal of the resulting ash have become an environmental and economic issue [8] as biomass ash represents $\sim 2-20 \%$ of input material.[9] Ash produced by biomass combustion tends to be a problematic waste because it may contain a relatively large portion of silicon oxide insoluble in most solvent and due to the fact that biomass ash often contains a low concentration of toxic metals such as lead, zinc or cadmium [10], which limits the possible applications of the ash in agriculture in some cases. If the produced biomass ash is uncontaminated, it can be used as a fertilizer. Nevertheless, if it contains a higher concentration of heavy metals [11], it has to be stored in landfills which are not only very expensive, but it also produces large volumes of waste. Moreover, a lot of facilities burn combined biofuels according to e.g. year seasons, therefore contamination of woodchip ash by other ash from other sources cannot be easily prevented. For example, Zluticka heating plant in the Czech Republic burns approximately 4000 tons of wooden chips and 1000 tons of wheat straw producing tens of tons of biomass ash every year. Hence it is of great importance to find a way how to utilize such ash, especially in the exact cases when its agricultural utilization is unsuitable.

Chemical processing of the ash can lead to obtaining various products. One of the best possible way how to use and immobilize waste produced from processed ash is its application in the construction industry in the form of composite construction material. In this paper, the possibility to use of a portion of processed woodchip ash is studied from the raw material to the final product and its performances. 


\section{EXPERIMENTAL}

\section{Biomass ash processing}

Wood Chips Ash was obtained from Žlutická heating plant in the Czech Republic. Ash (2000 g, sample termed as WCA) was put into a 501 round barrel filled with 401 of water. The barrel was subsequently rolled for $10 \mathrm{~min}$ to achieve homogenous suspension. Then the mixture was left to sediment for $1 \mathrm{~h}$. During this process, some non-burnt residues of carbonized wooden chips were flushed to the water surface. Carbonized Wooden Chips were removed from the surface, dried and weighed (CWC). Water containing basis was left to evaporate until a dry product with a high content of Alkaline Carbonates was achieved (AC) The procedure was repeated to decrease the content of potassium and sodium in ash. The settled material was dried and then heated to $600{ }^{\circ} \mathrm{C}$ for $12 \mathrm{~h}$ in a furnace with a dynamic air atmosphere (heating and cooling rates were $5^{\circ} \mathrm{C} \cdot \mathrm{min}^{-1}$ ). During this step remaining carbon was oxidized and obtained white-grey product was then sifted to remove rough Sintered Material (SM). After the sieving, the product was mixed with fine granulated sodium hydroxide with weight ratio $2: 3$. The mixture was heated in a steel container at $350{ }^{\circ} \mathrm{C}$ in a furnace for 2 hours in an air atmosphere, again with the same heating and cooling rate. The product was subsequently put into distilled water and mixed. Due to different sedimentation time, the product was divided into the Light Phase (LP) and Heavy Phase (HP). After the filtration of the solid content, the solution containing dissolved silicates was bubbled by carbon dioxide $\left(100 \mathrm{ml} \cdot \mathrm{min}^{-1}\right)$ for $2 \mathrm{~h}$. Finally, the suspension was centrifuged at $15000 \mathrm{rpm}$ for $30 \mathrm{~min}$ in order to obtain Amorphous Silica (AS). All fractions were analysed by X-ray fluorescence (XRF) and selected fractions were analysed by X-ray powder diffraction (XRD), energy dispersive spectroscopy (EDS) technique, and simultaneous thermal analysis (STA).

\section{Analytic techniques}

X-ray fluorescence (XRF) analysis was performed by ARL PERFORM'X sequential WD-XRF spectrometer equipped with an $\mathrm{Rh}$ anode end-window $\mathrm{X}$-ray tube type 4GN fitted with $50 \mu \mathrm{m}$ Be window. All peak intensity data were collected by software Oxsas in a vacuum. The generator settings-collimator-crystal-detector combinations were optimized for all 82 measured elements with an analysis time of $6 \mathrm{~s}$ per element. The obtained data were evaluated by software Uniquant 5 integrated in Oxsas. The analysed powders were pressed into pellets about $5 \mathrm{~mm}$ thick and diameter of $40 \mathrm{~mm}$ without any binding agent and covered with $4 \mu \mathrm{m}$ supporting polypropylene (PP) film.

X-ray diffraction (XRD) on PANalytical X'Pert PRO diffractometer in Bragg-Brentano parafocusing geometry using $\mathrm{CuK} \alpha$ radiation. Data evaluation was performed by means of the HighScore Plus software package and by KSoft [12].

The morphology was investigated using scanning electron microscopy (SEM) with a FEG electron source (Tescan Lyra dual beam microscope). Elemental composition and mapping were performed using an energy dispersive spectroscopy (EDS) analyser $\left(\mathrm{X}-\mathrm{Max}^{\mathrm{N}}\right)$ with a $20 \mathrm{~mm}^{2}$ SDD detector (Oxford Instruments) and AZtecEnergy software. To conduct the measurements, the samples were placed on a carbon conductive tape. SEM and SEM-EDS measurements were carried out using a $10 \mathrm{kV}$ electron beam.

Simultaneous thermal analysis (STA) was performed up to $1000{ }^{\circ} \mathrm{C}$. The measurement was conducted in an alumina crucible using Linseis PT 1600. The heating rate was set to $10{ }^{\circ} \mathrm{C} \cdot \mathrm{min}^{-1}$ and the measurement was carried out in a dynamic synthetic air atmosphere ( 20 vol. $\% \mathrm{O}_{2} / 80$ vol. $\% \mathrm{~N}_{2}$ ) with a flow rate $50 \mathrm{ml} \cdot \mathrm{min}^{-1}$.

The particle size distribution of LP and HP products was tested using an apparatus Analysette 22 Micro Tec plus (Fritsch) working on a laser diffraction principle.

\section{Production of magnesium phosphate cement composites}

As the amount of synthetized ultrafine powders HP and LP was relatively high and based on their chemical and mineralogical composition, they were used in the composite mix as partial silica sand substitution. The sand replacement ratio was $30 \mathrm{wt}$. \%. Binder was based on magnesium phosphate cement (MPC) as it can found use as an adhesive, cement or as a coating for materials, therefore providing a wide range of applications. [13] Although the phosphate binder is more expensive compared to Portland cement, the chemical processing of the binder makes it inexpensive in high volume production. [14] In order to reduce binder cost and hence product cost, fly ash can be used as a partial replacement for the binder. The addition of fly ash to sulphate cement composites has been reported to generate more binder, contribute to strength increase, and improve the bonding between fly ash and phosphate binder [15]. Therefore, the use of biomass ash residuals in the composite mix could possibly bring benefits to the improvement of binder properties. The magnesium oxide used was DBM 88, a heavy magnesium oxide from Slovenské magnezitové závody Jelšava, Inc., Slovakia. It had following chemical composition (data given in wt. \%): $\mathrm{SiO}_{2} 0.4 \%, \mathrm{Fe}_{2} \mathrm{O}_{3}$ $8.16 \%, \mathrm{Al}_{2} \mathrm{O}_{3} 0.19, \mathrm{CaO} 2.19 \%, \mathrm{MgO} 88.96 \%$. Depending on the $\mathrm{CaO} / \mathrm{SiO}_{2}$ ratio these residual oxides react with each other to form different secondary phases that coexist with $\mathrm{MgO}$ in the material [16]. For example, calcium silicate phases react with water forming $\mathrm{C}-\mathrm{S}-\mathrm{H}$ phase [17]. Monopotassium phosphate $\mathrm{KH}_{2} \mathrm{PO}_{4}$, a white crystalline product with p.a. quality was purchased from Lach-Ner, s.r.o., Czech Republic. Molar ratio of $\mathrm{MgO}$ and $\mathrm{KH}_{2} \mathrm{PO}_{4}$ was 8:1. In reference composite mix (MPM), 
the $0-2 \mathrm{~mm}$ aggregate was mixed from three silica sand fractions $0-0.5 \mathrm{~mm}, 0.5-1 \mathrm{~mm}$, and $1-2 \mathrm{~mm}$, in a weight ratio of 1:1:1. It was a product of Filtrační písky Ltd., Czech Republic. HP and LP powders were due to their particle size used as microfiller optimizing sand grading curve, i.e., $200 \mathrm{~g}$ of HP and LP mix in a mass ratio of 2:1 was added to sand mix composed of $200 \mathrm{~g}$ of each original sand fraction. The water to binder ratio w/b was 0.4 and was similar for both researched composites. The composition of studied materials is given in Table 1.

The test specimens were standard prisms having dimensions of $40 \times 40 \times 140 \mathrm{~mm}$. The freshly cast specimens were freely left in the laboratory at a temperature of $(22 \pm 2){ }^{\circ} \mathrm{C}$ and $\mathrm{RH}$ of $(50 \pm 3) \%$.

Table 1. Mix design of magnesium-based phosphate cement composites.

\begin{tabular}{lccccccc}
\hline & \multicolumn{7}{c}{ mass (g) } \\
\cline { 2 - 8 } Material & $\mathrm{MgO}$ & $\mathrm{KH}_{2} \mathrm{PO}_{4}$ & $\mathrm{HP}$ & $\mathrm{LP}$ & sand & water & $\mathrm{v} / \mathrm{b}$ \\
\hline MPM $_{\text {ref }}$ & 563 & 237 & - & - & 800 & 320 & 0.4 \\
MPM_HLP & 563 & 237 & 133.5 & 66.5 & 600 & 320 & 0.4 \\
\hline
\end{tabular}

Methods of testing hardened
composites

For 28 days samples, experimental tests for the assessment of their structural and mechanical properties were conducted. In these experiments, experimental procedures designed originally for mortars testing were used.

Among basic structural properties, bulk density, specific density, total open porosity and pore size distribution were measured. Before these tests, the specimens were dried in a vacuum drier at $60{ }^{\circ} \mathrm{C}$. The specific density $\rho_{s}\left(\mathrm{~g} \cdot \mathrm{cm}^{-3}\right)$ was measured using helium pycnometry. The bulk density $\rho_{b}\left(\mathrm{~g} \cdot \mathrm{cm}^{-3}\right)$ of composite specimens was determined according to the EN 1015-10 from the measurement of specimen dry mass and its volume [18]. The expanded combined uncertainty of the bulk density test was $2.4 \%$. On the basis of bulk density and matrix density values, the total open porosity $\psi(\%)$ was calculated [19]. The expanded combined uncertainty of the total open porosity test was $3.5 \%$. The pore size distribution was measured using mercury porosimeters Pascal 140 and Pascal 440 (Thermo). The typical specimens mass was about $0.9-1.0 \mathrm{~g}$.

The strength tests were conducted according to the standard EN 1015-11 [20]. The flexural strength $f_{f}(\mathrm{MPa})$ was accessed on rectangular prism specimens in three-point bending test arrangement. The compressive strength $f_{c}(\mathrm{MPa})$ was measured on the fragments of specimens from the flexural strength testing. The loading area was $40 \times 40 \mathrm{~mm}$. The relative expanded uncertainty of strength tests was $1.4 \%$. The Young's modulus $E_{d}$ (GPa) was obtained on a dynamic principle using the pulse ultrasonic method. The measurement was done on rectangular prisms in a longitudinal direction using a DIO 562 apparatus (Starmans Electronic). The expanded combined uncertainty of this test was $5.6 \%$.

STA of hardened composites was conducted using a similar procedure as given above for WCA, FP, and PL high-temperature tests (see section 3).

Mortar specimens were also studied using DinoLite digital optical microscope with a resolution of $5 \mathrm{Mpx}$.

\section{RESULTS AND DISCUSSION}

We processed Wood Chips Ash (WCA) and obtained six different fractions: Carbonized Wooden Chips (CWC), Alkaline Carbonates (AC), Sintered Material (SM), Light Phase (LP), Heavy Phase (HP) and Amorphous Silica (AS). Photography of all samples can be seen in Figure 1.

At the beginning, $2 \mathrm{~kg}$ of WCA were used. During the water treatment of ash, some non-burnt residues of light carbonized wooden chips (CWC) were flushed to the water surface. We obtained $\sim 80 \mathrm{~g}$ of CWC that can be used again as a fuel. Water was highly alkaline $(\mathrm{pH} \sim 11)$ confirming that potassium, sodium and some calcium was dissolved. After the drying low amount ( $\sim 50 \mathrm{~g})$ of alkaline carbonates was achieved (AC). Because of the

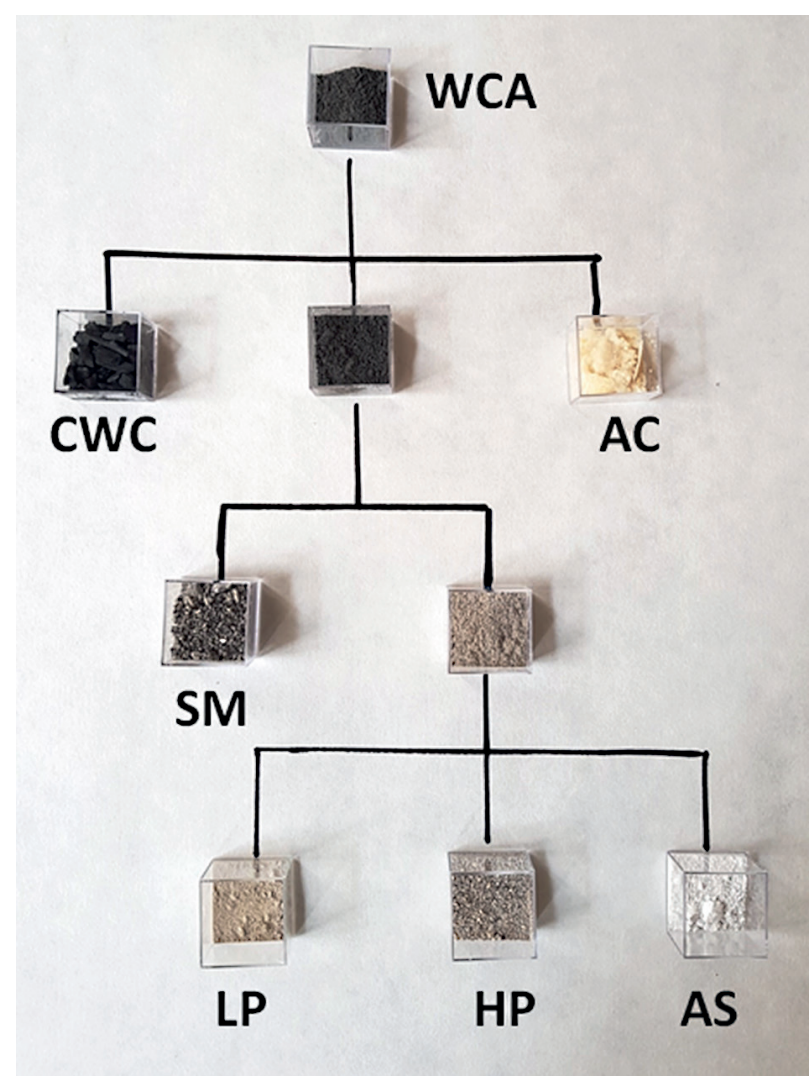

Figure 1. Photography of samples after the processing of biomass ash. 
extremely long process and low yield this fraction has no application potential. After the thermal treatment and sieving, $\sim 630 \mathrm{~g}$ of sintered material (SM) was obtained. This hard material can be theoretically further used as a filler or lightweight aggregate in the composite mix design. Purpose of another thermal treatment of the purified ash with sodium hydroxide was to transform insoluble silica to soluble silicates which may be separated by water leaching. After the thermal treatment and separation of products, we obtained $\sim 280 \mathrm{~g}$ of heavy phase (HP), $\sim 690 \mathrm{~g}$ of light phase (LP) and $\sim 15 \mathrm{~g}$, of amorphous silica (AS) [21]. Amount of silica was relatively low; however, ultrafine powders of HP and LP can be further processed in building materials. Let us note that same loss occurred due to the analysis of samples and also during the heating some carbon was oxidized.

X-ray fluorescence was used to co analyse the chemical composition of obtained products. Results are summarized in Table 2. It was confirmed that CWS contained mainly light elements hence it can be used again as a fuel. Alkaline carbonates (AC) contained except $\mathrm{CaCO}_{3}, \mathrm{~K}_{2} \mathrm{CO}_{3}$, and $\mathrm{Na}_{2} \mathrm{CO}_{3}$ also relatively high content of chlorides and sulfates, confirming their high solubility in water. SM fraction, highly sintered material, contained a mixture of almost all elements that were present in ash suggesting the presence of various alumino-silicates. Interestingly the composition of LP suggests the presence of almost pure $\mathrm{CaCO}_{3}$. HP also contained the majority of $\mathrm{CaCO}_{3}$ but it also contained a relatively high amount of silicon. AS fraction contained except silica also high content of aluminum and zinc, most probably in form of oxides. This is interesting because during this step we can remove zinc that is dangerous for the environment.
This can be easily explained, while during the treatment with $\mathrm{NaOH}$, soluble compounds such as $\mathrm{Na}\left[\mathrm{Al}(\mathrm{OH})_{4}\right]$, $\mathrm{Na}_{2}\left[\mathrm{Zn}(\mathrm{OH})_{4}\right]$ and $\mathrm{Na}_{2} \mathrm{SiO}_{3}$ were formed. After the leaching, the solution was acidified by carbon dioxide hence non-soluble oxides participated from the alkaline solution. Based on these results we decided to further analyse only HP and LP that can be further processed in construction and building materials.

Table 2. XRF analysis of individual fractions from the starting biomass ash (WCA). The first line of the table showed the content of light elements.

\begin{tabular}{crrrrrrr}
\hline & WCA & CWC & AC & \multicolumn{1}{c}{ SM } & LP & HP & AS \\
\cline { 2 - 8 } & \multicolumn{7}{c}{ (wt. \%) } \\
\hline $\mathrm{C}+\mathrm{O}+(\mathrm{N})$ & 76.02 & 97.95 & 55.08 & 57.23 & 65.46 & 65.83 & 48.37 \\
$\mathrm{Al}$ & 1.02 & 0.05 & 0.01 & 5.42 & 1.49 & 1.32 & 7.66 \\
$\mathrm{Ba}$ & 0.06 & 0.01 & 0.00 & 0.11 & 0.09 & 0.09 & 0.16 \\
$\mathrm{Ca}$ & 13.17 & 0.86 & 26.18 & 13.57 & 27.97 & 21.02 & 3.25 \\
$\mathrm{Cl}$ & 0.70 & 0.04 & 0.93 & 0.02 & 0.01 & 0.02 & 0.04 \\
$\mathrm{Fe}$ & 0.69 & 0.03 & 0.00 & 4.72 & 0.47 & 1.59 & 0.08 \\
$\mathrm{~K}$ & 2.08 & 0.59 & 15.47 & 1.45 & 0.16 & 0.55 & 1.59 \\
$\mathrm{Mg}$ & 0.80 & 0.10 & 0.04 & 2.79 & 1.53 & 1.42 & 0.20 \\
$\mathrm{Mn}$ & 0.06 & 0.00 & 0.00 & 0.11 & 0.10 & 0.10 & 0.00 \\
$\mathrm{Na}$ & 0.18 & 0.02 & 1.28 & 0.58 & 0.09 & 0.15 & 2.94 \\
$\mathrm{P}$ & 0.71 & 0.11 & 0.00 & 0.88 & 0.85 & 0.63 & 0.12 \\
$\mathrm{~Pb}$ & 0.02 & 0.00 & 0.00 & 0.00 & 0.00 & 0.00 & 0.02 \\
$\mathrm{Rb}$ & 0.01 & 0.00 & 0.04 & 0.01 & 0.00 & 0.00 & 0.01 \\
$\mathrm{~S}$ & 0.31 & 0.12 & 0.71 & 0.13 & 0.06 & 0.09 & 0.02 \\
$\mathrm{Si}$ & 3.70 & 0.09 & 0.03 & 12.05 & 1.21 & 6.60 & 33.15 \\
$\mathrm{Sr}$ & 0.17 & 0.02 & 0.22 & 0.13 & 0.14 & 0.15 & 0.14 \\
$\mathrm{Ti}$ & 0.17 & 0.01 & 0.00 & 0.80 & 0.24 & 0.41 & 0.00 \\
$\mathrm{Zn}$ & 0.10 & 0.01 & 0.01 & 0.01 & 0.03 & 0.02 & 2.32 \\
\hline
\end{tabular}

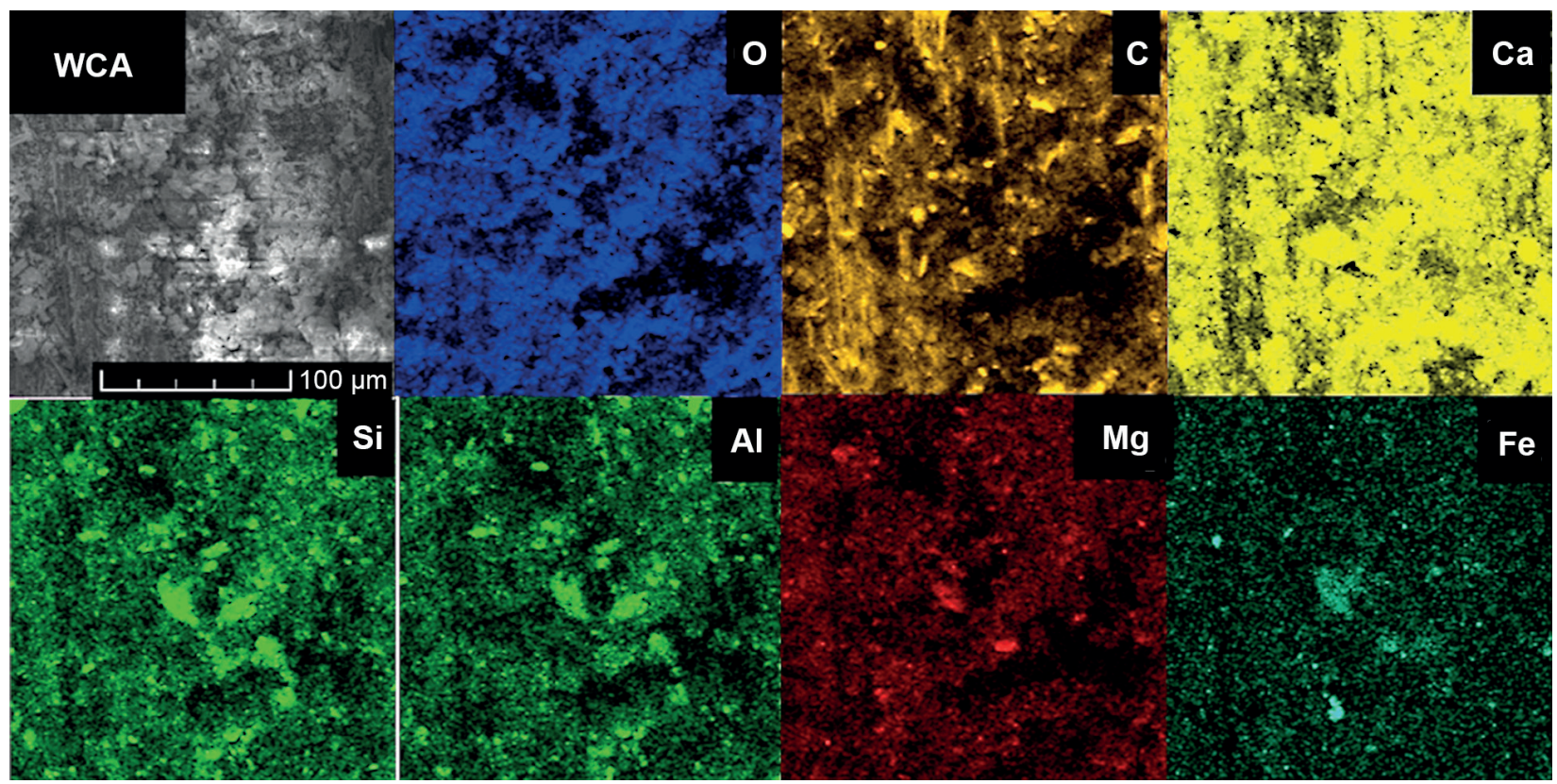

a) WCA

Figure 2. Elemental distribution maps of WCA, LP and HP. (Continue on next page) 

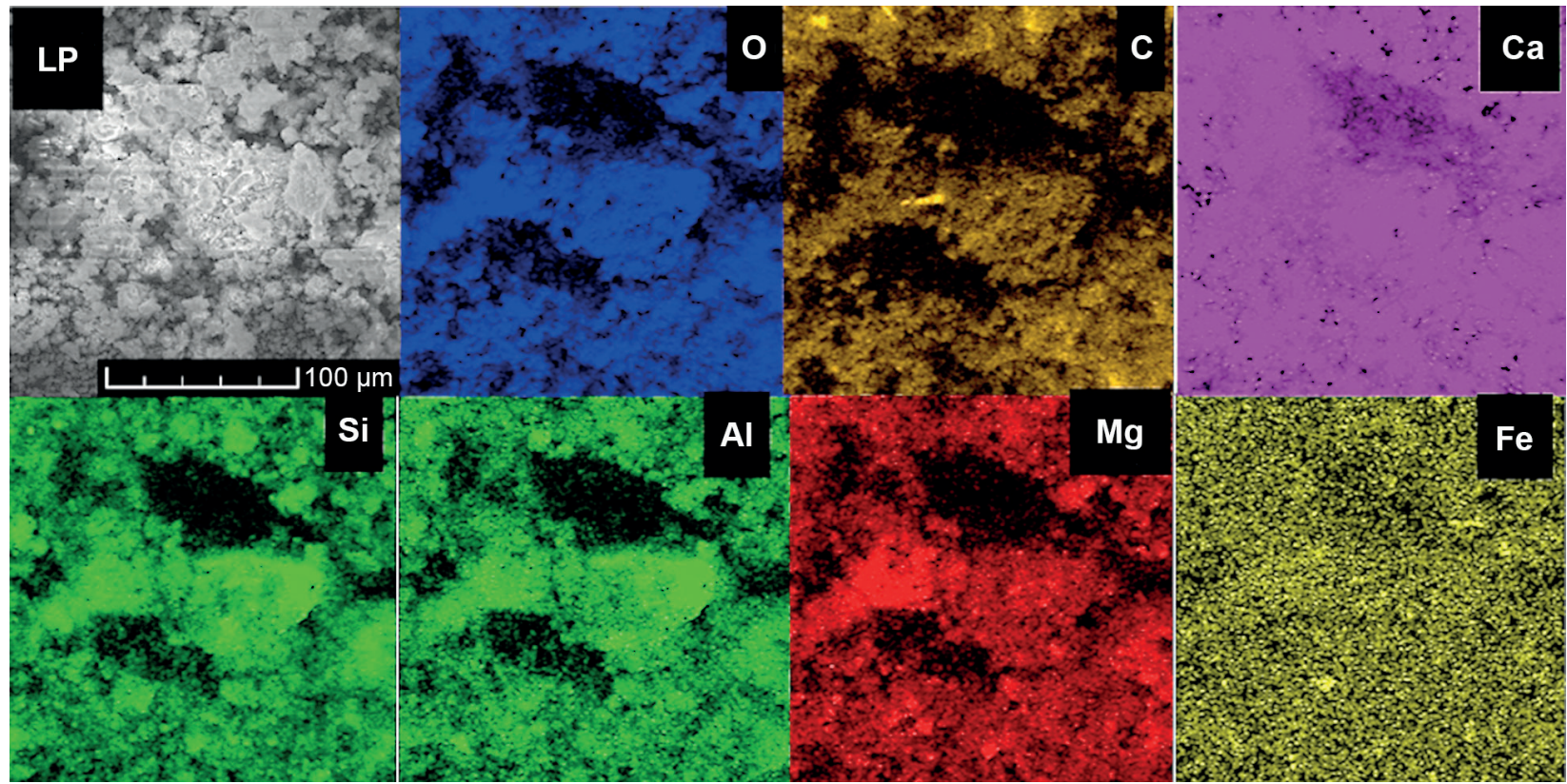

b) LP

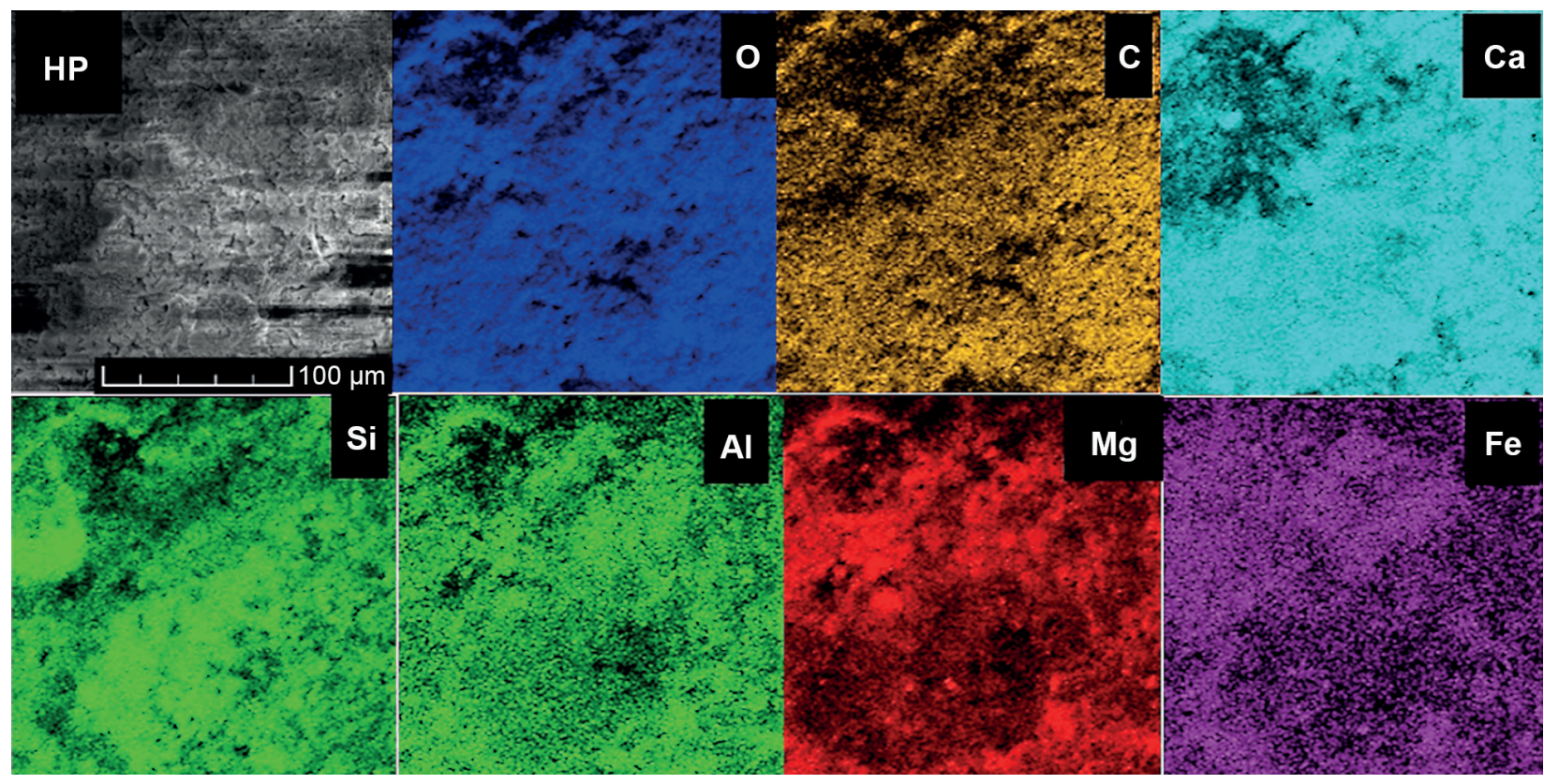

c) HP

Figure 2. Elemental distribution maps of WCA, LP and HP.

HP and LP were also analysed by energy dispersive spectroscopy (EDS) to confirm the chemical composition and also to analyse elemental distribution maps. Results are shown in Table 3. Obtained results confirmed results from XRF. Let us note, that EDS is not such sensitive in comparison to XRF, hence not all present elements were detected. Elemental distribution maps for LP and HP for the major elements $(\mathrm{O}, \mathrm{C}, \mathrm{Ca}, \mathrm{Si}, \mathrm{Al}, \mathrm{Mg}, \mathrm{Fe})$ are shown in Figure 2. Results of obtained elemental maps will be discussed together with results from XRD. Also, the elemental maps of the starting sample WCA are shown in this figure showing a high content of carbon. The micro- structure of WCA, LP, and HP is shown in Figure 3. In HP and LP there are particles smaller than $10 \mu \mathrm{m}$. In the case of WCA, there are also some large particles that are unburnt carbon residues.

Light phase, heavy phase, and biomass ash were also analysed by XRD to obtain the phase composition. Diffractograms are shown in Figure 4. Starting material WCA contained a high amount of calcite, and lower amounts of calcium oxide, calcium hydroxide, quartz and also other minor phases. As we expected the major phase in LP sample was calcite (JCPDS 01-081-2027). This was also confirmed by elemental maps (EDS). 
In the sample HP, a mixture of various phases was detected. Two major phases were calcite and quartz (JCPDS 03-065-0466), they were found in ratio $\sim 3: 2$. Also, some minor phases were detected such as $\mathrm{Ca}_{2} \mathrm{SiO}_{4}$, $\mathrm{KAlSi}_{2} \mathrm{O}_{6}$ and other modifications of $\mathrm{SiO}_{2}$. This is in good agreement with EDS elemental maps and elemental composition obtained by EDS and XRF.

Table 3. EDS analysis of LP, HP and biomass ash (WCA).

\begin{tabular}{lccc}
\hline & WCA & LP & HP \\
\hline $\mathrm{O}$ & 30.3 & 46.2 & 49.3 \\
$\mathrm{C}$ & 39.7 & 14.9 & 14.3 \\
$\mathrm{Ca}$ & 16.2 & 30.1 & 18.4 \\
$\mathrm{Si}$ & 3.6 & 2.7 & 6.5 \\
$\mathrm{Al}$ & 1.0 & 2.0 & 1.9 \\
$\mathrm{Mg}$ & 0.9 & 1.8 & 4.1 \\
$\mathrm{Fe}$ & 0.8 & 1.1 & 3.4 \\
$\mathrm{P}$ & 0.9 & 0.8 & 0.3 \\
$\mathrm{~K}$ & 4.9 & 0.1 & 1.0 \\
$\mathrm{Ti}$ & 0.4 & 0.2 & 0.5 \\
$\mathrm{Na}$ & 0.2 & 0.1 & 0.4 \\
$\mathrm{~S}$ & 0.5 & 0.0 & 0.0 \\
$\mathrm{Cl}$ & 0.4 & 0.0 & 0.0 \\
$\mathrm{Zn}$ & 0.2 & 0.0 & 0.0 \\
\hline
\end{tabular}

Thermal behavior of WCA, LP, and HP was also analysed by simultaneous thermal analysis (see Figure 5). A huge exothermal effect was observed for WCA with the maximum at $\sim 440{ }^{\circ} \mathrm{C}$. This effect was connected to $\sim 10 \%$ weight decrease due to the combustion/oxidation of soot and remaining carbonized wood chips. The second endothermal effect between $700{ }^{\circ} \mathrm{C}$ and $800^{\circ} \mathrm{C}$ was the decomposition of calcium carbonate, also for this effect, TG curve showed $\sim 12 \%$ weight decrease due to the evolution of carbon dioxide. The DTA signal of the sample LP showed one small exothermic effect between $250{ }^{\circ} \mathrm{C}$ and $450{ }^{\circ} \mathrm{C}$ accompanied by slight weight decrease that can be caused due to the water release from calcium hydroxide or sorbed water. The major endothermal effect between $700{ }^{\circ} \mathrm{C}$ and $850{ }^{\circ} \mathrm{C}$ was caused

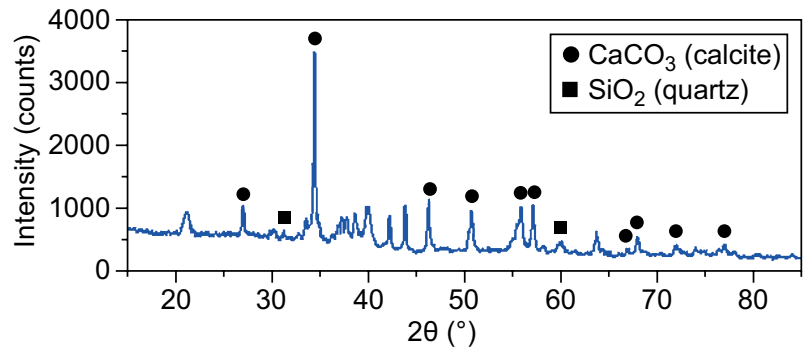

a) WCA

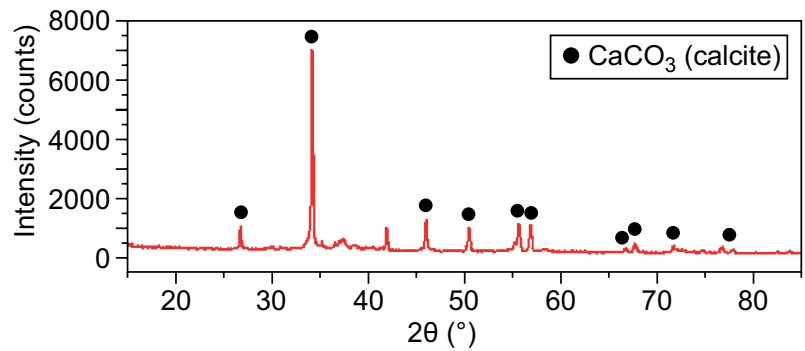

b) LP

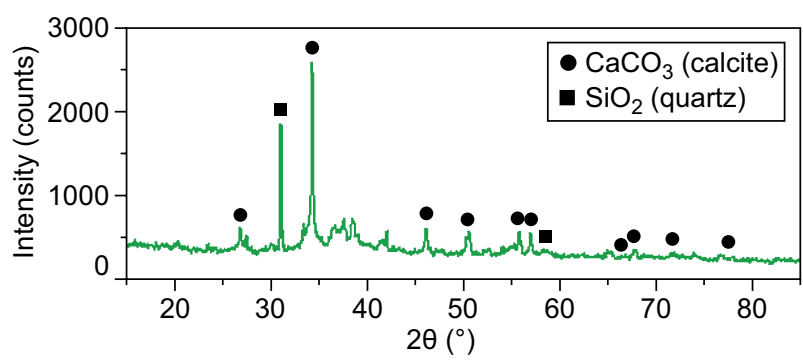

c) $\mathrm{HP}$

Figure 4. XRD diffraction patterns for LP and HP.

due to the decomposition of calcium carbonate forming calcium oxide. This effect was accompanied by a sudden weight decrease. The sample lost over 32 wt. \% during the heating confirmed high content of calcium carbonate. Very similar behavior was obtained for sample HP; however, much lower endothermic effect was observed due to the lower content of calcium carbonate. The sample lost only $\sim 14$ wt. $\%$ during heating.

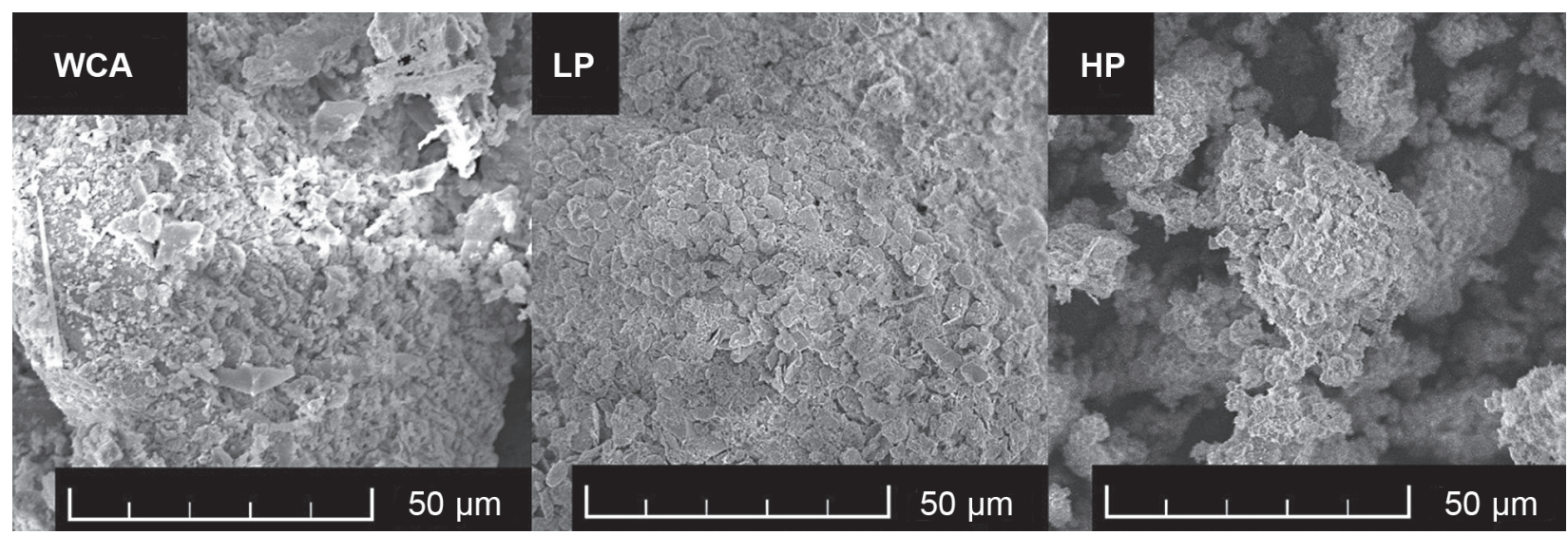

Figure 3. Elemental distribution maps of WCA, LP and HP. 


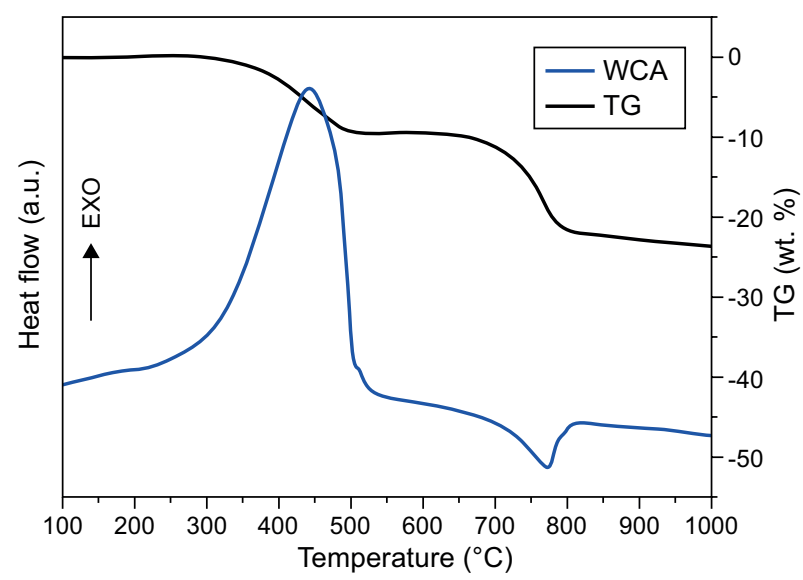

a) WCA

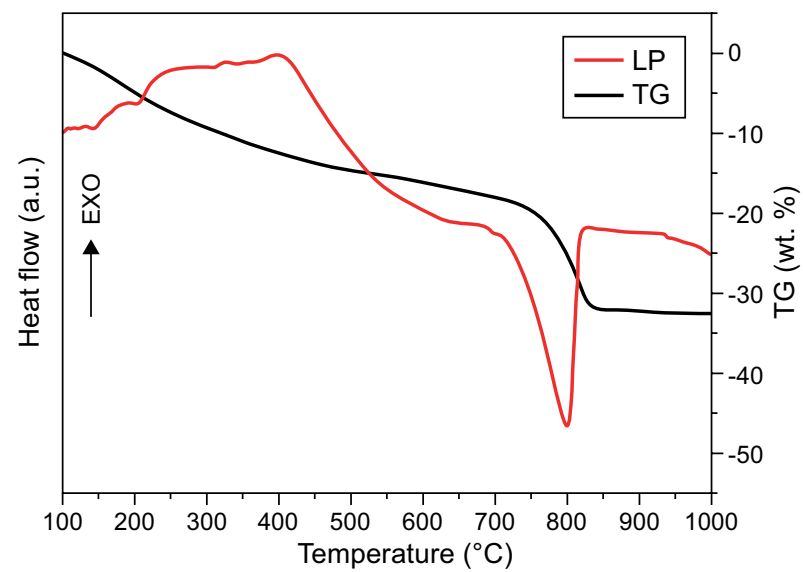

b) LP

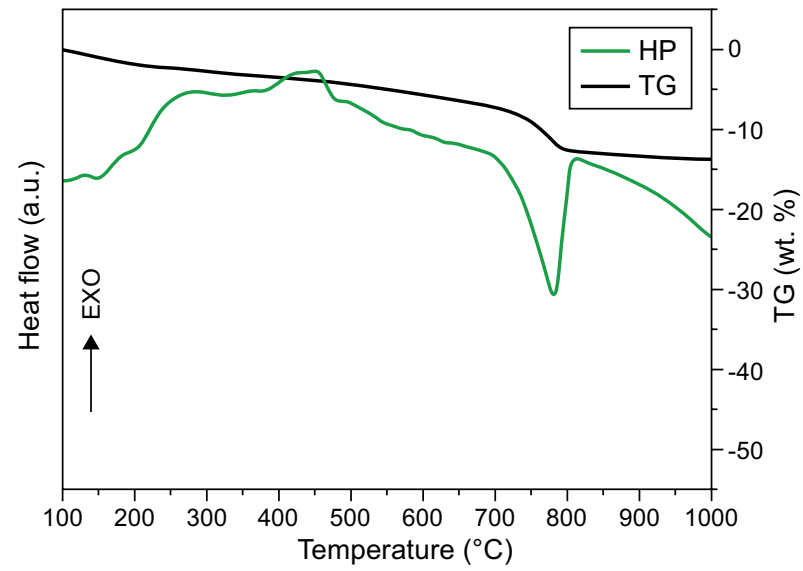

c) HP

Figure 5. STA of WCA, LP, and HP in a dynamic air atmosphere.
Particle size distribution of LP and HP measured by laser diffraction is shown in Figure 6. Powder LP had particles in the range from $0.1 \mu \mathrm{m}$ to approx. $150 \mu \mathrm{m}$ with a maximum of particle size distribution curve at approx. $51 \mu \mathrm{m}$. Material HP was coarser com-pared to LP. It exhibited particles in the range of approx. 0.1$550 \mu \mathrm{m}$ with a maximum of particle size distribution curve at $56 \mu \mathrm{m}$. Based on their particle size, both LP and HP powders were used as sand substitutes in composite mix composition, supplementing its grading curve.

Basic structural properties of examined magnesium phosphate cement composites are together with MIP data summarized in Table 4. The partial silica sand replacement with LP and HP mix led to the decrease in the bulk density, and thus to the increase in the total open porosity compared to the reference material without processed biomass ash. Similar porosity values were obtained also by mercury intrusion porosimetry test. On the other hand, the average pore diameter was similar for both studied materials. As reported Colorado at al. [22] the porosity of phosphate cement products can be controlled by changing the mixing parameters. In our case, the porosity and thus bulk density values corresponded with results published in a paper written by Colorado et al. [23]. Authors reported on the density of phosphate cement based products varying from $1.8 \mathrm{~g} \cdot \mathrm{cm}^{-3}$ to $2.4 \mathrm{~g} \cdot \mathrm{m}^{-3}$. The increase in porosity can be partially assigned to the slight worsening of MPM_HLP mix workability due to the higher specific surface and moisture absorption of LP and HP particles compared to silica sand.

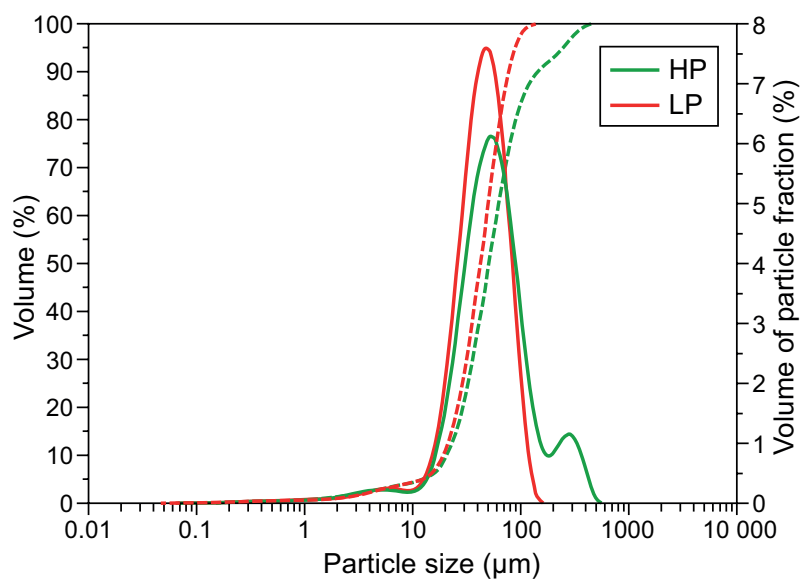

Figure 6. Particle size distribution - cumulative and distribution curves.

Table 4. Basic structural properties.

\begin{tabular}{lccccc}
\hline Material & $\begin{array}{c}\text { Bulk density } \\
\rho_{b}\left(\mathrm{~g} \cdot \mathrm{cm}^{-3}\right)\end{array}$ & $\begin{array}{c}\text { Specific density } \\
\rho_{\mathrm{s}}\left(\mathrm{g} \cdot \mathrm{cm}^{-3}\right)\end{array}$ & $\begin{array}{c}\text { Total open porosity } \\
\Psi(\%)\end{array}$ & $\begin{array}{c}\text { Mercury porosity } \\
\psi_{\mathrm{Hg}}(\%)\end{array}$ & $\begin{array}{c}\text { Average pore diameter } \\
(\mu \mathrm{m})\end{array}$ \\
\hline MPM $_{\text {ref }}$ & 1.9 & 2.80 & 32.1 & 31.8 & 6.21 \\
MPM_HLP & 1.8 & 2.81 & 35.9 & 34.5 & 6.32 \\
\hline
\end{tabular}


Table 5. Mechanical parameters.

\begin{tabular}{lccc}
\hline Material & $\begin{array}{c}\text { Compressive strength } \\
f_{c}(\mathrm{MPa})\end{array}$ & $\begin{array}{c}\text { Flexural strength } \\
f_{f}(\mathrm{MPa})\end{array}$ & \multicolumn{2}{c}{ Young's modulus } \\
$E_{d}(\mathrm{GPa})$
\end{tabular}

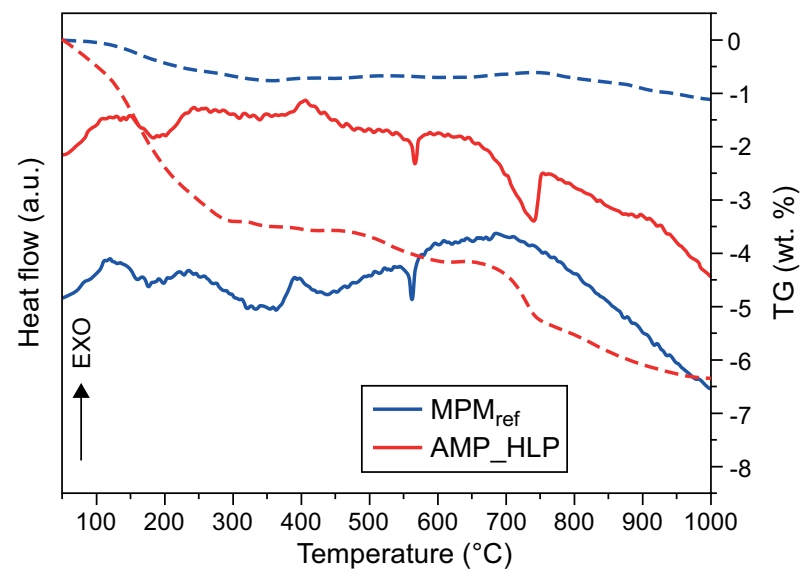

Figure 7. STA of hardened MPC composites.

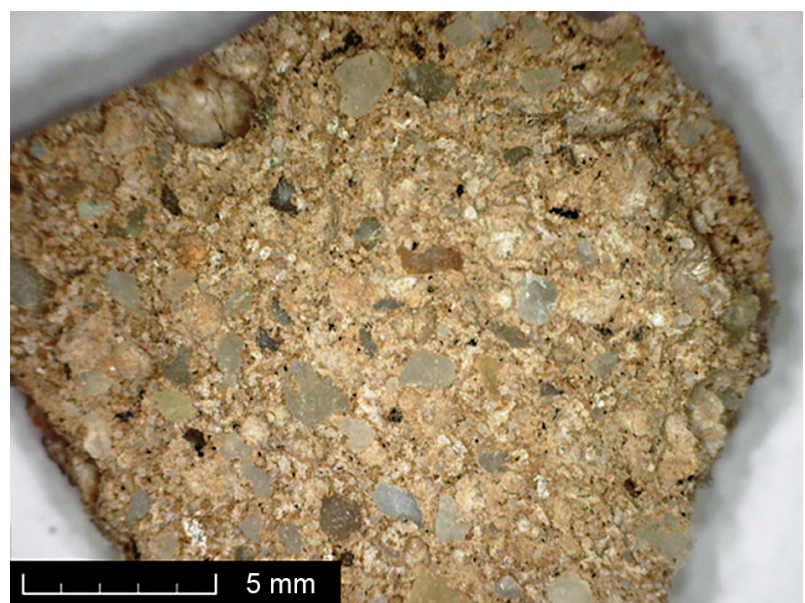

a) HP

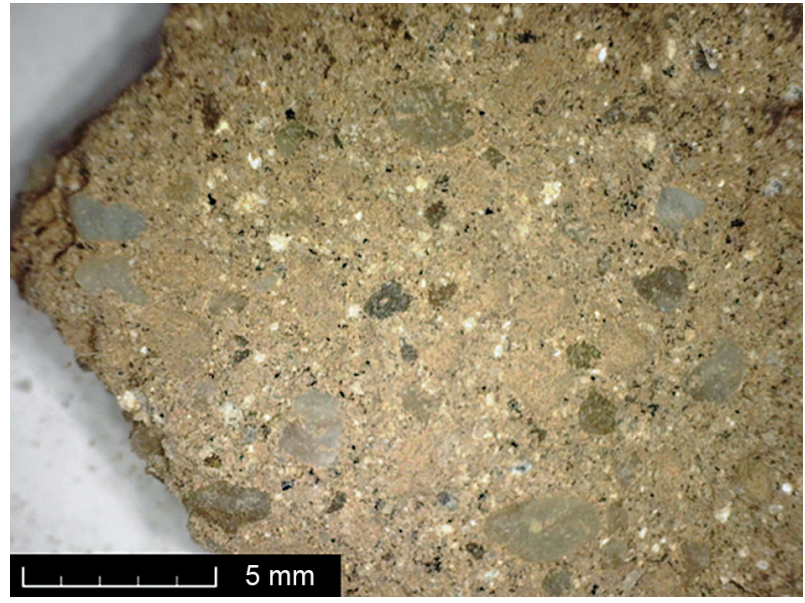

c) HP
Mechanical resistance of phosphate cement composites composed of silica sand filler was high as typical for MPC-based materials. The use of LP and HP in the composite mix had no negative effect on investigated mechanical parameters considering the increased porosity of MPM_HLP. It has clearly proved the ability of products of wood chips ash processing in such type of applications. As mechanical properties were only slightly affected for MPM-HLP material and as reported, e.g., by Chen et al. [24], fly ash and silica fume improves water resistance of MPC mortars, similar improved durability in respect to moisture action can be predicted also in our case.

Results of high-temperature analysis of hardened samples are given in Figure 7. As can be seen from

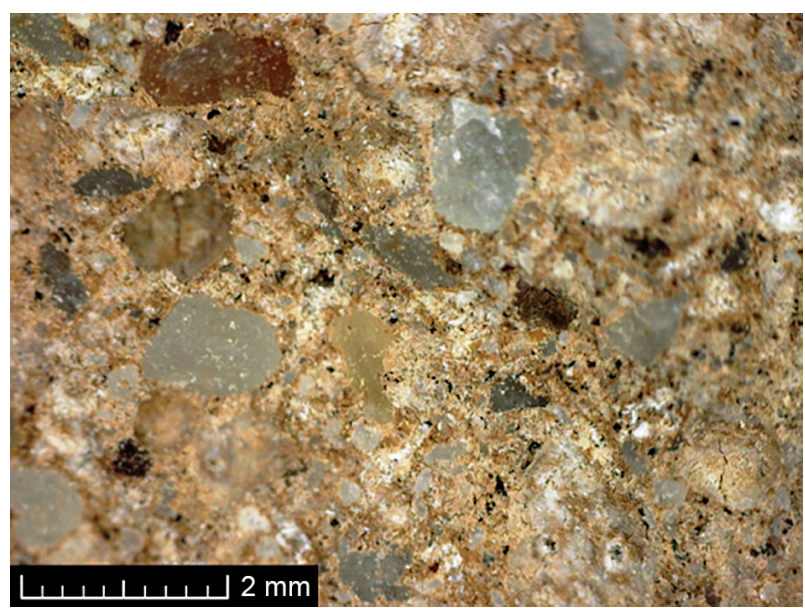

b) HP

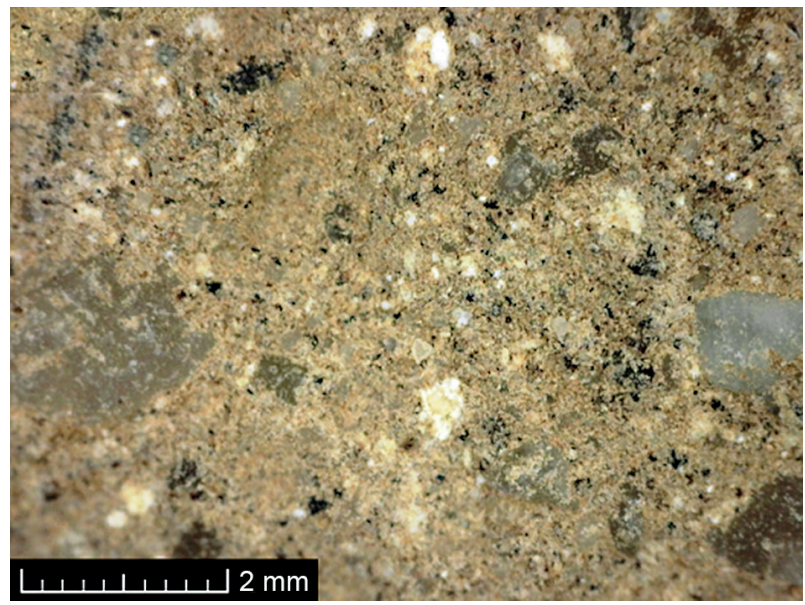

d) HP

Figure 8. Optical microscopy of MPC composites. 
TG curves, the main water losses were observed for both materials up to $\sim 150{ }^{\circ} \mathrm{C}$. This can be assigned to the dehydration of struvite- $\mathrm{K}$ [25]. The weight loss at higher temperatures (around $200{ }^{\circ} \mathrm{C}$ ) could be associated with the thermal decomposition of unreacted residual $\mathrm{KH}_{2} \mathrm{PO}_{4}$ [26]. The endothermic peak with a maximum at around $570{ }^{\circ} \mathrm{C}$ can be attributed to the phase transition of $\alpha-\beta$ quartz. [27] The endothermic effect observed at a temperature range of $700-800{ }^{\circ} \mathrm{C}$ in the sample containing LP and HP admixtures was due to the decomposition of calcium carbonate [28, 29], as described in the thermal behavior of the individual LP and HP samples.

The optical microscopy images of both examined materials are shown in Figure 8. Macroscopically, the differences between the studied composites were low; both materials had dense structure point out the good incorporation of silica sand grains in MPC matrix. As part of silica filler was replaced in MPM-HLP composition by LP and HP mix, the number of silica grains was visibly lower in $\mathrm{MPM}_{\text {ref }}$ images.

\section{CONCLUSIONS}

Biomass ash coming from wood chips combustion was chemically processed. The chemical processing of the used ash led in particular production stages to various products. After the second thermal treatment and separation of products, we have obtained heavy sintered phase (HP), light sintered phase (LP) and amorphous silica (AS). Amount of silica was relatively low; however, ultrafine powders LP and HP were further processed in the production of magnesium-based phosphate cement composite. The major phase in LP composition was calcite. In HP, a mixture of various phases such as calcite, quartz, aluminosilicates and other $\mathrm{SiO}_{2}$ forms were detected. As HP and LP materials exhibited proper particle size distribution, their mix was used as partial sand substitution improving its grading curve. The phosphate binder had a faster setting and a low carbon footprint compared to its Portland cement counterpart. The composite with incorporated products of WCA processing showed acceptable structural and mechanical properties that were almost unchanged compared to those measured for control material. Based on that it can be concluded that magnesium based phosphate binder is robust enough to accommodate solid residuals from biomass ash processing considering their chemical and mineralogical composition. The developed composite can be used for example for finishing of interior walls and floor layers. In future work, authors recommend testing of other material properties, such as hygric and thermal, important for the use of designed composite in the construction industry. The lightweight alternatives of the developed composite must be also tested to develop material for thermal insulation panels and slabs.
Acknowledgment

Authors greatly acknowledge the financial support received from the Czech Science Foundation under project No 19-00262S - Reactive magnesia cementsbased composites with selected admixtures and additives.

\section{REFERENCES}

1. Spinelli R., Nati C., Sozzi L., Magagnotti N., Picchi G. (2011): Physical characterization of commercial woodchips on the Italian energy market. Fuel, 90(6), 2198-2202. Doi: 10.1016/j.fuel.2011.02.011

2. Toscano G., Duca D., Pedretti E. F., Pizzi A., Rossini G., Mengarelli C., Mancini M. (2016): Investigation of woodchip quality: Relationship between the most important chemical and physical parameters. Energy, 106, 38-44. Doi: 10.1016/j.energy.2016.03.037

3. Passey R., Spooner T., MacGill I., Watt M., Syngellakis K. (2011): The potential impacts of grid-connected distributed generation and how to address them: A review of technical and non-technical factors. Energy Policy, 39, 6280-6290. Doi: 10.1016/j.enpol.2011.07.027

4. González A., Riba J.-R., Puig R., Navarro P. (2015): Review of micro- and small-scale technologies to produce electricity and heat from Mediterranean forests' wood chips. Renewable and Sustainable Energy Reviews, 43, 143-155. Doi: 10.1016/j.rser.2014.11.013

5. Flores H. F. V., Furubayashi T., Nakata T. (2016): Decentralised electricity generation system based on local renewable energy sources in the Honduran rural residential sector, Clean Technologies and Environmental Policy, 18(3), 883-900. Doi: 10.1007/s10098-015-1067-x

6. Petersen J. P. (2016): Energy concepts for self-supplying communities based on local and renewable energy sources: A case study from northern Germany. Sustainable Cities and Society, 26, 1-8. Doi: 10.1016/j.scs.2016.04.014

7. Nunes L. J. R., Matias J. C. O., Catalão J. P. S. (2016): Biomass combustion systems: A review on the physical and chemical properties of the ashes. Renewable and Sustainable Energy Reviews, 53, 235-242. Doi: 10.1016/j.rser. 2015.08.053

8. Vassilev S. V., Baxter D., Andersen L. K., Vassileva C. G. (2013): An overview of the composition and application of biomass ash. Part 1. Phase-mineral and chemical composition and classification. Fuel, 105, 40-76. Doi: 10.1016/j. fuel.2012.09.041

9. Jenkins B., Baxter L., Miles Jr T., Miles T. (1998): Combustion properties of biomass, Fuel processing technology, 54, 17-46. Doi: 10.1016/S0378-3820(97)00059-3

10. Obernberger I., Brunner T., Bärnthaler G. (2006): Chemical properties of solid biofuels - significance and impact. Biomass and Bioenergy, 30, 973-982. Doi: 10.1016/j.biombioe. 2006.06.011

11. Sander M. L., Andren O.: Ash from cereal and rape straw used for heat production: Liming effect and contents of plant nutrients and heavy metals. Water, air, and soil pollution, 93(1-4), 93-108 (1997). Doi: 10.1023/A:1022179708289

12. Jankovsky O., Sedmidubsky D., Sofer Z., Simek P., Hejtmanek J. (2012): Thermodynamic Behavior of $\mathrm{Ca}_{3} \mathrm{Co}_{3.93+x} \mathrm{O}_{9+\delta}$ Ceramics. Ceramics-Silikáty, 56, 139-144. 
13. Amiandamhen S., Meincken M., Tyhoda L. (2016): Magnesium based phosphate cement binder for composite panels: A response surface methodology for optimisation of processing variables in boards produced from agricultural and wood processing industrial residues. Industrial crops and products, 94, 746-754. Doi: 10.1016/j.indcrop.2016.09.051

14. Colorado H., Hiel C., Hahn H. T., Yang J.-M.(2011). Wollastonite-based chemically bonded phosphate ceramic composites. In Metal, Ceramic and Polymeric Composites for various uses. IntechOpen. Doi:10.5772/17120

15. Zhu D., Zongjin L. (2005): Study of high early strength cement based on fly ash, magnesia and phosphate. Materials Technology, 20, 136-141. Doi: 10.1080/10667857.2005. 11753125

16. Jastrzębska I., Szczerba J., Prorok R., Śnieżek E. (2015): An experimental study on hydration of various magnesia raw materials. Ceramics-Silikáty, 59, 48-58.

17. Sutcu M., Akkurt S., Okur S. (2009): Influence of crystallographic orientation on hydration of $\mathrm{MgO}$ single crystals. Ceramics International, 35, 2571-2576. Doi: 10.1016/ j.ceramint.2009.02.012

18. EN 1015-10 (2000). Methods of test for mortar for masonry - Part 10: Determination of dry bulk density of hardened mortar, European Committee for Standardization. Brussels.

19. Jankovský O., Pavlikova M., Sedmidubský D., Bouša D., Lojka M., Pokorný J., Zaleska M., Pavlík Z. (2017): Study on pozzolana activity of wheat straw ash as potential admixture for blended cements. Ceramics-Silikáty, 61, 327-339. Doi: 10.13168/cs.2017.0032

20. EN 1015-11 (1999). Methods of test for mortar for masonry - Part 10: Determination of flexural and compressive strength of hardened mortar, European Committee for Standardization. Brussels.

21. Zaleska M., Pavlikova M., Jankovsky O., Pokorny J., Pavlik Z. (2018): Lightweight concrete made with waste expanded polypropylene-based aggregate and synthetic coagulated amorphous silica. Ceramics-Silikáty, 62, 221-232. Doi: $10.13168 / \mathrm{cs} .2018 .0015$
22. Colorado H., Hahn H., Hiel C. (2011): Pultruded glass fiberand pultruded carbon fiber-reinforced chemically bonded phosphate ceramics. Journal of Composite Materials, 45, 2391-2399. Doi: 10.1177/0021998311401090

23. Colorado H., Hiel C., Hahn H. (2011): Chemically bonded phosphate ceramics composites reinforced with graphite nanoplatelets. Composites Part A: Applied Science and Manufacturing, 42, 376-384. Doi: 10.1016/j.compositesa. 2010.12.007

24. Jiang Y., Ahmad M. R., Chen B. (2019): Properties of magnesium phosphate cement containing steel slag powder. Construction and Building Materials, 195, 140-147. Doi: 10.1016/j.conbuildmat.2018.11.085

25. Zhang S., Shi H.-S., Huang S.-W., Zhang P. (2013): Dehydration characteristics of struvite-K pertaining to magnesium potassium phosphate cement system in non-isothermal condition. Journal of thermal analysis and calorimetry, 111, 35-40. Doi: 10.1007/s10973-011-2170-9

26. Xu B., Ma H., Shao H., Li Z., Lothenbach B. (2017): Influence of fly ash on compressive strength and microcharacteristics of magnesium potassium phosphate cement mortars. Cement and Concrete Research, 99, 86-94. Doi: 10.1016/j.cemconres.2017.05.008

27. Rickard W. D., Riessen A. v., Walls P. (2010): Thermal character of geopolymers synthesized from class $\mathrm{F}$ fly ash containing high concentrations of iron and $\alpha$-quartz. International Journal of Applied Ceramic Technology, 7 , 81-88.

28. Villain G., Thiery M., Platret G. (2007): Measurement methods of carbonation profiles in concrete: Thermogravimetry, chemical analysis and gammadensimetry. Cement and Concrete Research, 37, 1182-1192. Doi: 10.1016/j.cemconres.2007.04.015

29. Pavlíková M., Zemanová L., Pokorný J., Záleská M., Jankovský O., Lojka M., Sedmidubský D., Pavlík Z. (2018): Valorization of wood chips ash as an eco-friendly mineral admixture in mortar mix design. Waste Management, 80, 89-100. Doi: 10.1016/j.wasman.2018.09.004 